\title{
A IMPORTÂNCIA DA SUBJETIVIDADE NO PROCESSO DE FORMAÇÃO DO LEITOR
}

\author{
Debora Dietsche. Graduanda em Letras Vernáculas, UEL. \\ Tahera Fortunato Zaraket. Graduanda em Letras Vernáculas, UEL.
}

\section{RESUMO}

O processo de formação do leitor é uma ação em constante andamento, e o imaginário em torno da relação entre a leitura e o leitor é elemento relevante nesse desenvolvimento. Afirmação esta, que, em geral é desconsiderada nos documentos oficias, como PCN e DCE, pois percebemos que estes apresentam um imaginário idealizado, onde a formação do leitor é baseada na concepção de que um ambiente favoravelmente letrado e estável são suficientes ao aluno. O leitor/aluno real é desconsiderado, assim também é o contexto no qual vive, pois procura-se generalizar os leitores e as leituras de um país inteiro num mesmo modelo. Além desses documentos, textos consagrados como o de João Ubaldo Ribeiro reforçam esse imaginário ideal. Contudo, José Paulo Paes e Graciliano Ramos desconstroem esse mito, mostrando-nos ambientes e percepções distintos que formam um leitor tão competente quanto o leitor construído no modelo imaginário ideal. Pois, através de diversos temas inseridos em suas obras, procuram mostrar as diferentes opiniões e ideias a respeito do processo de formação dos leitores. Assim, olhamos com outra concepção para o processo de formação, sendo este como algo subjetivo e múltiplo que favorece o trabalho do docente no desenvolvimento do aluno como leitor real.

Palavras-chave: leitura, subjetividade, formação.

\section{INTRODUÇÃO}

O processo de formação do leitor é uma ação em contínuo andamento, e depende de vários fatores, tanto ambientais como também pessoais/individuais. O leitor pode desenvolver-se em ambientes pouco letrados, como também não se adaptar ao nível elevado de letramento no qual está inserido. Existe uma ilusão a respeito da relação entre os ambientes letrados e o consequente desenvolvimento positivo do leitor. Os documentos oficiais PCN e DCE, que são norteadores na construção dos currículos, ajudam a difundir tal imaginário. Os textos oficiais também cultivam a ideia de que o ambiente é o estabelecedor do nível da capacidade de leitura do indivíduo. Há relatos que reforçam tal imaginário, como o do escritor João Ubaldo Ribeiro, pois o ambiente no qual o mesmo cresceu foi grande influenciador no seu processo de formação como leitor. Ao contrário, José Paulo Paes e Graciliano Ramos, evidenciam processos distintos de engajamento com a leitura. A escola possui grande peso na formação do leitor, por se basear nos PCN e nas DCE, corre o risco de considerar a relação entre o ambiente letrado e a formação do leitor como algo correspondente. É importante ressaltar que não basta o aluno ter acesso aos livros para garantir sua formação leitora, por outro lado, o aluno que não tiver as mesmas oportunidades de ambientes letrados não estará, necessariamente, fadado ao fracasso. Nesse sentido, é importante ressaltar que cada indivíduo 


\section{SEMINÁRIO DE PESQUISA EM CIÊNCIAS HUMANAS - SEPECH \\ Humanidades, Estado e desafios didático-científicos \\ Londrina, 27 a 29 de julho de 2016}

vivencia uma experiência em sua formação, portanto, a subjetividade é essencial na vinculação do leitor com o texto e com a leitura. Neste artigo, apresentaremos a análise de depoimentos de três autores, João Ubaldo Ribeiro, José Paulo Paes e Graciliano Ramos, nos quais há um contraste nas histórias de formação leitora e também nos ambientes de letramento.

\section{JOÃO UBALDO RIBEIRO: CONTEXTO E PERCURSO DE LETRAMENTO}

João Ubaldo Osório Pimentel Ribeiro é baiano, natural de Itaparica, onde nasceu em janeiro de $1941^{1}$. Ribeiro passou grande parte de sua infância na Bahia, onde cresceu com a sua família. Seu pai era professor e político. Ribeiro formou-se em Direito, porém nunca chegou a advogar. Fez sua pós-graduação e mestrado na área de administração. Foi também professor em diversos centros de educação na Bahia. Era jornalista, escrevia para diversos jornais, atuando em diferentes funções no Brasil, mas também no exterior, como na Alemanha, Inglaterra e Portugal. Começou a escrever suas obras literárias ainda quando estudante e chegou a participar do International Writing Program na Universidade de Iowa, nos Estados Unidos. Atuou em várias áreas como escritor, fosse como romancista, jornalista, tradutor ou cronista.

João Ubaldo recebeu vários prêmios pelas suas obras, um deles foi o Prêmio Golfinho de Ouro, obtido pelo romance Sargento Getúlio (1971). Também ocupou a cadeira $\mathrm{n}^{\circ} 34$, na Academia Brasileira de Letras, a partir de 1993. João Ubaldo faleceu em 2014, deixando aos seus leitores suas diversas obras.

Neste artigo em específico, iremos analisar o texto "Memória de Livros", que integra a obra Um brasileiro em Berlim (1995), texto importante por evidenciar a trajetória de vida e a formação do leitor, que posteriormente tornar-se-ia o escritor João Ubaldo Ribeiro.

No texto Memória de Livros, João Ubaldo Ribeiro escreve sobre o processo de como vivenciou a sua formação como leitor. Ele narra através de sua memória onde morava, no interior de Sergipe, em uma cidade pequena longe dos grandes centros de comércio. A família tinha boas condições e possuía os mais novos eletrodomésticos. Seu pai incentivava os filhos, desde cedo, a terem curiosidade pela leitura. A família era considerada obcecada pela leitura, havia livros por toda a casa, e reservavam muito espaço para eles. Ubaldo não soube especificar quando exatamente aprendeu a ler, pois desde pequeno estivera em constante contato com letras e símbolos. Ele teve facilidade em aprender a ler, pois desde pequeno encontrava-se envolvido com o mundo dos livros. E no processo de aprendizagem, notou que as letras que via a sua frente começavam a significar algo, e tornaram-se vivas.

À mãe, chamava a atenção essa relação especial que o filho tinha com a leitura, mas para o pai parecia extremamente normal a grande quantidade de livros que o menino lia. O pai achava positiva a paixão que o filho tinha pela leitura, apesar de, desde pequeno, orientá-lo: "Ele está cheirando os livros certos, mas lendo o dicionário er

\footnotetext{
${ }^{1}$ Dados biográficos foram baseados nas informações disponíveis na página da Academia Brasileira de Letras, disponível em: <http://www.academia.org.br/academicos/joao-ubaldo-ribeiro>. Acesso em: 2 mai. 2016.
} 


\section{SEMINÁRIO DE PESQUISA EM CIÊNCIAS HUMANAS - SEPECH \\ Humanidades, Estado e desafios didático-científicos \\ Londrina, 27 a 29 de julho de 2016}

rado, precisa de orientação" (p. 145). Nesse trecho, os pais discutem sobre o fato de o filho ler dicionários, o pai acha bom o filho ter esse tipo de leitura, mas não o exemplar em específico que estava lendo. Percebe-se que o pai tem grande influência sobre os textos que o filho lê, pois sempre está orientando o mesmo. Ubaldo cita dois tipos de leituras que eram feitas, a compulsória e a livre. Através das leituras compulsórias, o pai cobrava os textos lidos de alguma maneira, fosse pedindo um resumo, dando uma aula sobre o assunto do texto ou sobre o seu autor. João Ubaldo lembra em especial das leituras livres, que podiam tornar-se perigosas, pois de vez em quando o pai proibia a leitura de certas obras. $\mathrm{O}$ que as tornava ainda mais interessantes. Ubaldo acreditava que isso seria uma jogada de seu pai, pois entendia a curiosidade das crianças pelo proibido, como se fizesse de propósito - "e hoje penso que li tudo o que ele queria disfarçadamente que eu lesse" (RIBEIRO, 1995, p. 147).

Não é apenas a posição do pai em relação à leitura que é mostrada, mas também a da avó e do avô. Ao contrário do pai, a avó dava ao pequeno Ubaldo liberdade para ler o que bem entendesse. Os dois iam juntos às livrarias comprar novas obras e passavam muito tempo comentando as leituras.

Ubaldo cita alguns dos muitos clássicos que leu durante a infância e destaca a importância que tiveram em sua vida, apesar de muitos deles terem sido adaptações, resumos, discussões etc. $\mathrm{O}$ escritor ressalta que apesar de parecer ter tido uma infância muito diferente das outras crianças, também praticava atividades consideradas 'normais' para a idade em questão. "Os livros eram brincadeira como outra qualquer, embora certamente a melhor de todas" (RIBEIRO, 1995, p. 153). Ubaldo descreve parte de sua infância, caracterizando-a positivamente, através das suas memórias. É interessante notar a importância, em parte, da família no processo de formação do leitor, como o pai e os avós incentivaram-no, como os livros e a velha casa provocam um sentimento de nostalgia em João Ubaldo Ribeiro.

O contexto, em parte, tem grande influência na formação do leitor, no caso de João Ubaldo, sua família o estimulou muito à leitura. $\mathrm{O}$ ambiente em que nasceu favoreceu o seu contato com os livros, também o seu futuro como escritor, pois seus familiares também tinham o hábito de ler. Portanto, fica ressaltado em seu depoimento que o contexto pode facilitar ou dificultar a formação do leitor. As emoções carregam um papel fundamental no ato de ler: "...o engajamento afetivo é de fato um componente essencial da leitura em geral" (JOUVE, 2002, p. 21). Percebe-se esse engajamento afetivo no momento em que o pai de João Ubaldo proíbe a leitura de certas obras, o que acarretou na intensificação da vontade de lê-las.

"Mas, depois que completei seis anos, ele não aguentou, fez um discurso dizendo que eu já conhecia todas as letras e agora era só uma questão de juntá-las e, além de tudo, ele não suportava mais ter um filho analfabeto" (RIBEIRO, 1995, p. 142). No trecho acima percebe-se que o pai de Ubaldo interveio muito no processo de formação do seu filho como leitor, e Ubaldo via essa interferência como positiva, mesmo que para nós, leitores do texto, o pai pareça ter um posicionamento muito rígido e controlador. Ubaldo lembra de sua infância com certa saudade, havendo uma idealização desse contexto.

O processo de formação exemplificado no texto "Memórias de Livros", pode ser considerado um modelo ideal, pois Ubaldo, já na sua infância gostava muito de ler. 


\section{SEMINÁRIO DE PESQUISA EM CIÊNCIAS HUMANAS - SEPECH \\ Humanidades, Estado e desafios didático-científicos \\ Londrina, 27 a 29 de julho de 2016}

Hábito que muitos não têm desde cedo, às vezes por falta de estímulo das pessoas à sua volta, ou até mesmo pela falta de interesse ou por fatores muito particulares, que extrapolam o aspecto social relacionado à questão.

É interessante notar as diferenças entre o Ubaldo antes de ser capaz de ler textos, e o Ubaldo 'leitor'. No trecho transcrito abaixo, João Ubaldo ainda não conseguia ler as palavras, porém era capaz de atribuir às imagens o significado que desejava dar. "Quando havia figuras, eu inventava as histórias que elas ilustravam e, ao olhar para as letras, tinha a sensação de que entendia nelas o que inventara" (RIBEIRO, 1995, p. 142). Portanto, mesmo não entendendo o significado das palavras, Ubaldo era capaz de dar à história o significado que desejava: “... de repente o mundo mudou e aquelas paredes cobertas de livros começaram a se tornar vivas..” (RIBEIRO, 1995, p. 144).

Conforme dissemos acima, a experiência vivida por João Ubaldo Ribeiro parece exemplar, reforçando um imaginário constituído por afirmações de que a formação do leitor resulta fortemente das suas condições de letramento. No documento oficial PCN, é citado que:

Formar leitores é algo que requer, portanto, condições favoráveis para a prática de leitura - que não se restringem apenas aos recursos materiais disponíveis, pois, na verdade, o uso que se faz dos livros e demais materiais impressos é o aspecto mais determinante para o desenvolvimento da prática e do gosto pela leitura (BRASIL, 1998, p. 43)

Entende-se que a escola é outro mecanismo que ajuda a formar o leitor, e suas condições e práticas de leitura espelham, em parte, no futuro aluno como leitor. Nota-se que a infância de Ubaldo é parecida com as condições apontadas pelo PCN, pois Ubaldo também tinha à sua disposição materiais para praticar a sua leitura. $O$ documento oficial também aponta a questão da frequência da prática da leitura, visto que é um processo de constante aprimoramento, como é exposto no texto de Ubaldo, ele quando pequeno tinha o costume de ler com frequência, muito influenciado também pela sua família, que possuía esse hábito.

É necessário notar, entretanto, que o contexto não é a única condição formadora do leitor. É possível considerar a situação em que João Ubaldo viveu sua infância, e pensar que ele poderia ter desenvolvido um sentimento negativo em relação a seu pai e à prática da leitura. Esse seria o caso de Paes, pois o que vem despertar o leitor, no segundo caso aqui analisado, não se encontra na ambiência familiar privilegiada, mas na escola, na biblioteca.

\section{JOSÉ PAULO PAES: CONTEXTO SEMELHANTE, OUTRO PERCURSO}

José Paulo Paes (1926 - 1998) nasceu em Taquaritinga, interior de São Paulo. Foi poeta, tradutor, ensaísta e crítico literário. Foi criado na casa de seu avô materno, proprietário de uma livraria, o que fez o contato do autor com a leitura mais fácil. Fluente em língua inglesa e francesa, que aprendeu no ginásio, e, posteriormente em russo, italiano e grego, que aprendeu sozinho com sua capacidade autodidata, Paes foi tradutor de inúmeros livros. 


\title{
XI SEMINÁRIO DE PESQUISA EM CIÊNCIAS HUMANAS - SEPECH \\ Humanidades, Estado e desafios didático-científicos \\ Londrina, 27 a 29 de julho de 2016
}

Na leitura do livro autobiográfico Quem, eu? Um poeta como outro qualquer, Paes conta sobre uma fase de sua vida que caracteriza como importante na sua formação literária: das leituras como momentos de entretenimento. A escola, a princípio, não estimulava a leitura de obras literárias, como o autor diz, somente pedia que os alunos lessem livros didáticos, das matérias do programa: aritmética, História do Brasil etc. Porém, sentia-se estimulado indiretamente pelos adultos de sua família, os quais transmitiam um ar de superioridade por se divertirem praticando a leitura:

\begin{abstract}
A leitura era um hábito cultivado quase por todos em casa de meu avô. Nós, crianças, tínhamos inveja dos adultos que conseguiam se distrair tanto tempo com aqueles risquinhos de tinta preta no branco da página e nós sentíamos inferiorizados por não entender nada do que significavam. Tal sentimento de inferioridade era um estímulo natural para o aprendizado das primeiras letras. (PAES, p. 14, 1996)
\end{abstract}

Entretanto, logo após esse relato, o autor faz uma crítica à família brasileira, pois, dentro de seus lares, o hábito da leitura, como meio de distração, não existe e se não fosse por isso, talvez, as escolas não teriam de impor leituras maçantes como dever de casa, algo obrigatório, porque, como ele mesmo explica, uma atividade não é prazerosa quando se é obrigatória. "De qualquer modo" afirma o autor "antes ler livros por obrigação do que não ler coisa alguma" (PAES, 1996, p. 14).

Contudo, o poeta conta que, quando criança, interessava-se pelas histórias de fadas, bruxas e gigantes, cheias de emoção e comédia. As leituras desses romances, segundo Paes, fizeram-no um leitor com uma carreira ininterrupta. Assim, é possível tomar conhecimento do quanto uma leitura que agrade e que estimule a imaginação de uma criança pode ser importante, porque não deverá ser a leitura de um poema complexo, por mais bonito que possa ser, que irá conquistar uma criança. Paes (1996, p. 15) conta como aprendeu a escrever para o público infantil estimulado por suas leituras de Monteiro Lobato: "Aprendi que é pelo trampolim do riso, não pela lição de moral, que se chega ao coração das crianças".

Durante a infância, Paes alternava as horas da leitura prazerosa com as horas de brincar na rua. Até esse ponto, o poeta era um leitor de livros infantis e fica claro como era ele quem decidia o que leria, diferente de João Ubaldo Ribeiro, em que o pai dava dicas e também 'proibições' de leitura. Paes não buscou os livros que sua família lia, muito menos os livros do colégio, pois, conforme mostra em um trecho do relato, chegou a argumentar consigo mesmo sobre um poema apresentado em sala de aula: "Quanta besteira, pensava comigo. Quem seria descuidado a ponto de perder um relógio de bolso com corrente e tudo?" (PAES,1996, p. 16). O interessante é que Paes buscava prazer no que lia e foi importante para ele essa independência de escolher seus livros.

O poeta mudou-se de Taquaritinga para Araçatuba, com a finalidade de buscar um melhor estudo. Foi nesse novo colégio que Paes começou a se interessar por Francês, Português e Literatura. Ele cita seus professores do ensino fundamental e até compara os professores de Francês: "A pronúncia clara do Prof. França e a sua pedagogia bem dosada me reconciliaram com a matéria que o Dr. Aristides me fizera detestar" (PAES, 1996, p. 22). Não é só nessa passagem que o autor comenta sobre a metodolo 


\section{SEMINÁRIO DE PESQUISA EM CIÊNCIAS HUMANAS - SEPECH \\ Humanidades, Estado e desafios didático-científicos \\ Londrina, 27 a 29 de julho de 2016}

gia de seus professores. Mais adiante, é possível ver como ele descreveu as aulas de seu professor de Português ${ }^{2}$, que ficaram marcadas ao ponto de detalhá-las:

Para o resto da vida sou devedor do Prof. Júlio Ridolfo, que nos ensinou, a mim e aos meus colegas relapsos, como redigir em português correto. Isso sem obrigar-nos a decorar regra após regra ou classificar uma por uma as orações das primeiras estrofes de Os lusíadas. De cada três aulas que dava, apenas uma era consagrada a explicações teóricas. Na seguinte, tínhamos de fazer em classe uma redação, de no mínimo dez linhas, sobre um tema por ele indicado. Quem terminasse a sua, podia entregá-la e ir para o recreio antes do fim da aula. O Prof. Ridolfo levava as redações para sua casa e as corrigia pacientemente com tinta vermelha. Na outra aula, comentava conosco os erros cometidos e nos explicava como evitá-los. E isso sempre com um bomhumor que nos gravava indelevelmente a explicação na mente. Eu gostava de procurar no dicionário palavras difíceis para enfeitar as minhas redações. Muitas vezes, enquadrá-las no tema dado pelo Prof. Ridolfo exigia prodígios de imaginação que muito o divertiam. (PAES, 1996, p.22.)

É curioso como seu professor manobrava suas aulas, deixando uma para explicações, outra para a produção e a última para as revisões e explicações dos erros cometidos, pois assim mostra-se um docente que preza em internalizar uma gramática contextualizada em seus aprendizes e colocá-la em prática, fazendo o aluno exercitar o que fora aprendido. Além disso, ele não somente apontava os erros, mas os explicava à classe como não cometê-los novamente. Por parte de Paes, é viável observar que existia um interesse pelo bom humor do professor e o estímulo que este provocava ao ponto de fazer seu aluno procurar palavras difíceis para adornar suas produções.

Todavia, apesar do reconhecimento do bom trabalho de seu professor de Português, apenas no final do ensino fundamental que o poeta começou a ser cativado pela leitura "séria", dita deste modo por ele. Sendo assim, pode-se notar uma separação que faz entre a leitura de entretenimento e aquela que ambiciona também uma capacidade reflexiva maior. Ou seja, esse foi outro passo importante na formação como leitor: a saída dos textos infantis, romances de aventuras e gibis para as poesias de Edgar Alan Poe e Augusto dos Anjos e para os romances de Machado de Assis.

Em Poe, Paes conta que, além do encanto pela poesia desse autor, mostra uma admiração pelos vários significados que encontrava a cada releitura do "Nunca mais!" de 'O corvo', em seu livro Poesias. O mesmo ocorreu com Dom Casmurro, de Machado de Assis: quanto mais relia, enquanto crescia, mais amadurecia e aprofundava sua maneira de ver a obra, mostrando, assim, a grande importância da expansão do plano de conteúdo que o leitor carrega consigo. Por isso, para o poeta, seria curioso se repensar sobre o programa das leituras obrigatórias, pois em um único ano ler obra "x" e não re

\footnotetext{
${ }^{2}$ Aqui, Paes não explica detidamente se havia separações de professores entre as matérias de Português, Literatura e Redação, contudo, fica subentendido que esse professor juntava todas essas disciplinas em suas aulas de Português e Redação.
} 


\section{SEMINÁRIO DE PESQUISA EM CIÊNCIAS HUMANAS - SEPECH \\ Humanidades, Estado e desafios didático-científicos \\ Londrina, 27 a 29 de julho de 2016}

tomá-la nos anos seguintes não é o suficiente, visto que os leitores estão em constante amadurecimento e descobrimento.

Além disso, a leitura de Machado de Assis mostrou a Paes que não era necessário um romance ser recheado de aventuras ou heróis para cativar um leitor, e essa percepção já expõe uma ruptura com as leituras juvenis, que foram importantíssimas para a formação dele como leitor. Todavia, o destaque maior se volta a Augusto dos Anjos, que exibiu-lhe uma outra forma de se fazer poesia, diferente daquelas que estavam nos manuais de língua portuguesa. As angústias do poeta sobre a existência humana faziam com que Paes se impressionasse profundamente e logo depois começasse a imitar de modo falho seus poemas cemiteriais. Assim, Paes estampa que a admiração por certo autor, estimulou de alguma forma sua produção literária. É possível observar isso mais adiante, quando Paes entra em contato com outros escritores no Café de Belas Artes, em Curitiba. Além disso, revela que para se ser um bom poeta só talento não lhe é suficiente, tem de se ter um lastro cultural amplo e diversificado na medida do possível. Ou seja, antes de ser um bom escritor, é preciso ser um bom leitor, o qual carregue consigo cultura, antes de mais nada, porque só assim é possível ser um bom crítico e um indivíduo que saiba decifrar o mundo.

É importante ressaltar que Paes, em sua obra, nos mostra alguém desinteressado pelos estudos, pois não tinha interesse em cursar o Ensino Médio. Além disso, afirma que só ia bem nas matérias de Português, Redação e Francês, nas demais, tirava apenas o mínimo para passar para o ano seguinte. Quando concluiu o Fundamental, Paes faz o ensino técnico em Curitiba para Química, pois ele mesmo sabia que viver de livro, ninguém vivia e que, no contexto capitalista que vivia, o importante era, segundo ele, conquistar dinheiro fácil. Mesmo dessa forma, Paes não deixou de ser um autor, poeta, crítico, tradutor e professor excepcional. Escolher seus caminhos e ser um leitor autêntico, fizeram-no um profissional excelente. Por isso, Paes é um caso que foge dos padrões ideais difundidos pelos PCN, assim como também ocorre com Graciliano Ramos.

\section{GRACILIANO RAMOS: OUTROS CONTEXTOS, MAIS PERCURSOS}

Graciliano Ramos (1892-1953) nasceu em Quebrangulo, sertão de Alagoas. Viveu sua infância com seus pais e mais dezesseis irmãos na cidade de Viçosa, Alagoas, e Buíque, Pernambuco. Sendo assim, passou pelos períodos da seca e aprendeu a rigidez das relações humanas a partir da vivência com seu pai, que era um homem bruto.

Em seu livro, Infância, Ramos, no capítulo "Os Astrônomos", conta sua primeira relação com a leitura. Começa mostrando a situação precária na qual ele vivia, a diferença entre ele e seus vizinhos, que "eram garotos felizes, (...) andavam limpos, riam alto, freqüentavam escola decente e possuíam máquinas que rodavam como trens" (RAMOS, 2008, p. 168). Ele era o contrário disso e, aos nove anos, era quase um analfabeto. Sua escola interiorana mostra-se incapaz de ensinar os alunos, os quais pensavam que o local de estudo era uma espécie de prisão. Pela falta de estímulo e uma educação 'indecente', Ramos largou os livros.

Certo dia, em uma noite qualquer, o autor descreve seu primeiro contato com um romance. $\mathrm{O}$ impulsionador disso tudo foi seu pai, o qual ordenou ao filho a ler para ele após o jantar. Ramos diz que só o fato de seu "velho" dirigir-se a ele era novidade e como o contato com o objeto pedido já lhe causava repugnância. Implorando mental 


\section{SEMINÁRIO DE PESQUISA EM CIÊNCIAS HUMANAS - SEPECH \\ Humanidades, Estado e desafios didático-científicos \\ Londrina, 27 a 29 de julho de 2016}

mente que alguém interrompesse a noite, o autor, ainda menino, começou a leitura "gaguejando, gemendo uma cantinela medonha, indiferente à pontuação. (...) Parei surpreendido, virei a folha, continuei a arrastar-me na gemedeira, como um carro em estrada cheia de buracos" (RAMOS, p. 169).

No meio do capítulo, seu pai interrompeu o garoto e perguntou se este compreendia o que estava sendo dito no livro. Ele respondeu que não, então seu pai explicou a história. "Alinhavei o resto do capítulo, diligenciando penetrar o sentido da prosa confusa, aventurando-me às vezes a inquirir. E uma luzinha quase imperceptível surgia longe, apagava-se, ressurgia, vacilante, nas trevas do meu espírito" (RAMOS, p. 170).

Assim, o autor ficou alheio o resto do dia, pensando no romance, inquieto consigo mesmo e ansioso para o próximo encontrou que ocorre como o último: leitura emperrada, mal-entendidos, explicações. Na terceira noite, louco para saber mais daquela narrativa, o menino foi ao encontro do pai, que naquela noite estava sombrio e silencioso e afastou o filho com um gesto carrancudo. O mesmo que apresentou-lhe uma maravilhosa novidade, foi quem diminuiu suas esperanças. Ramos, magoado pela decepção, foi ter com Emília, sua prima descrita como bondosa, achando que tinha remédio para sua situação. A garota ouviu-lhe e perguntou porque ele não arriscava a leitura sozinho e Graciliano disse que era fraco mentalmente, pois não sabia compreender as palavras.

Emília combateu a minha convicção, falou-me dos astrônomos, indivíduos que liam o céu, percebiam tudo quanto há no céu. Não no céu onde moram Deus Nosso Senhor e Virgem Maria. Esse ninguém tinha visto. Mas o outro, o que fica por baixo do sol, da lua e das estrelas, os astrônomos conheciam perfeitamente. Ora, se eles enxergavam coisas tão distantes, por que não conseguiria eu adivinhar a página aberta diante dos meus olhos? Não distinguia as letras? Não sabia reuni-las e formar palavras? (RAMOS, p. 172)

Foi assim que Ramos tomou coragem para tentar decifrar o romance. $\mathrm{O}$ autor é um belo exemplo de que é possível se interessar pela leitura mesmo estando inserido num contexto difícil, sem estímulos contínuos e com uma alfabetização tardia. Mostra que nunca é tarde para começar a ler e mesmo assim, que é possível ser um excelente autor com todos esses percalços descritos por ele.

Observando sua narração, parece até impossível um autor como ele ter vivenciado experiências péssimas e traumatizantes com os livros, como foi o caso com seu pai e com a escola, afinal é autor de diversos livros importantíssimos para a construção da Literatura Brasileira. Por isso, mais uma vez, toma-se aqui outro exemplo de que a formação do leitor é algo muito subjetivo que não pode ser padronizado por normas, as quais determinam o que é certo e o que é errado para formar um leitor. Ramos tinha de tudo para afastar-se dos livros, porém, a partir de várias situações desagradáveis e apenas dois momentos de significativo afeto, ele persistiu, sua curiosidade foi maior. Sensibilizar-se com o romance foi o primeiro passo para a leitura daquele e de mais outros que o tornaram um grande leitor e romancista. 


\section{SEMINÁRIO DE PESQUISA EM CIÊNCIAS HUMANAS - SEPECH \\ Humanidades, Estado e desafios didático-científicos \\ Londrina, 27 a 29 de julho de 2016}

\section{CONSIDERAÇÕES FINAIS}

As histórias e os processos de formação dos leitores João Ubaldo Ribeiro, José Paulo Paes e Graciliano Ramos são muito diferenciados. Apesar das vivências, é possível compreender que o contexto familiar, escolar, econômico e social influenciam, mas não são determinantes no processo de desenvolvimento do leitor. Porém nos casos de Paes e Ramos, o interesse particular foi decisivo para se entregarem à leitura. Esse processo é subjetivo, não pode ser imposto nem pela família nem pela escola, pois é o leitor que faz a leitura. É preciso considerar o leitor real e as suas singularidades, para se pensar numa formação leitora significativa.

\section{REFERÊNCIAS}

BRASIL. Parâmetros Curriculares Nacionais (PCNs). Introdução. Ensino Fundamental. Brasilia: MEC/SEF, 1998.

JOUVE, Vincent. A leitura. São Paulo: UNESP, 2002.

RAMOS, Graciliano; Infância. 1. ed. Rio de Janeiro: MEDIAfashion, 2008.

RIBEIRO, João Ubaldo. Um brasileiro em Berlim. Rio de Janeiro: Nova Fronteira, 1995.

Site da Academia Brasileira de Letras. Disponível em: $<$ http://www.academia.org.br/academicos/joao-ubaldo-ribeiro $>$. Acesso em: 2 mai. 2016.

PAES, José Paulo; Quem eu? Um poeta como outro qualquer. São Paulo: Atual, 1996. 